\title{
The use of uniformly labelled substrates and mass isotopomer analysis to study intermediary metabolism
}

\author{
BY HEINER K. BERTHOLD*, LINDA J. WYKES, FAROOK \\ JAHOOR, PETER D. KLEIN AND PETER J. REEDS $\dagger$ \\ USDA/ARS Children's Nutrition Research Center, Department of Pediatrics, Baylor College of \\ Medicine, 1100 Bates Street, Houston, TX 77030, USA
}

Modelling and, hence, quantifying $\mathrm{C}$ flow through the so-called central pathways of metabolism (e.g. glycolysis, the Kreb's (TCA) cycle and gluconeogenesis) present considerable experimental challenges. Because these metabolic pathways are the common route leading to the oxidation of essentially all the organic macronutrients, they receive $\mathrm{C}$ from a wide variety of precursors. Compounds generated as intermediates of the pathways also provide the precursors for other biosyntheses (e.g. nucleoside, amino acid and lipid synthesis). As a consequence, models that aim to quantify the reactions in the central pathways must eventually account for the complications of multiple inputs and outputs. The presence of substrate cycles (e.g. the pyruvate-oxaloacetate-phosphoenolpyruvate and oxaloacetate-malate-fumarate cycles) at key regulatory points in these pathways further complicates the interpretation of isotopic experiments. The result is that obtaining answers to what are apparently simple questions concerning metabolism leads rapidly to more complicated theoretical and experimental exercises (for example, see Kelleher, 1986; Kelleher \& Masterson, 1992). A particularly useful example of this phenomenon is the large research effort that has gone into answering three related questions: What is the rate of gluconeogenesis? Does it vary with feeding status? What is the contribution of glucose, derived from gluconeogenesis, to hepatic glycogen synthesis? These questions still remain open (Wehmeyer et al. 1994).

At face value, it would seem to be perfectly reasonable to suppose that glucose, absorbed from the diet and presented to the liver in the hepatic portal venous blood, would be rapidly phosphorylated in the hepatocytes and equally rapidly incorporated into hepatic glycogen. However, a considerable body of evidence (summarized by McGarry et al. 1987) suggests that a substantial proportion of glycogen is derived from the hepatic metabolism of 3-C metabolites derived from glucose metabolized by extrahepatic tissues, the so-called indirect pathway of glycogen synthesis. The key pieces of evidence that led to this conclusion were:

(1) in vitro, but not in vivo, extracellular lactate is a more effective substrate for glycogen synthesis than extracellular glucose (Hems et al. 1972; Seglen, 1974);

(2) the incorporation of ${ }^{14} \mathrm{C}$ from ${ }^{14} \mathrm{CO}_{2}$ into glycogen (label incorporation that occurs by $C$ fixation in oxaloacetate via the pyruvate carboxylase ( $E C 6.4 .1 .1)$ reaction) leads to a higher isotopic enrichment in glycogen than in plasma glucose (Newgard et al. 1983);

(3) blockade of phosphoenolpyruvate carboxykinase (EC 4.1.1.49) in vivo, inhibits the glycogen formation and this inhibition can be relieved by the presence of glycerol (Sugden et al. 1983). The summation of this evidence was termed, by Katz \& McGarry (1984), the 'glucose paradox'.

* Present address: Abteilung für Klinische Pharmakologie, Medizinische Klinik der Universitat Bonn, Sigmund-Freud-Strasse 25, 5300 Bonn 1, Germany.

$\dagger$ For reprints. 
Until comparatively recently most of the work that sought to answer these questions was based on the use of radioisotopes. Three main approaches were used.

The first approach involved using the fact that during glycolysis the $\mathrm{H}$ atoms on $\mathrm{C}-3$ of glucose are lost at the triose isomerization step, so that when a load of $\left[3-{ }^{3} \mathrm{H}\right.$, $\left.\mathrm{U}-{ }^{14} \mathrm{C}\right]$ glucose is administered any deviation in the ${ }^{3} \mathrm{H}:{ }^{14} \mathrm{C}$ ratio in glycogen from that in the administered glucose is a measure of the operation of the glucose-lactate-glycogen, i.e. the Cori cycle. This gave widely varying results in different hands (cf Scofield et al. 1985; Katz et al. 1986). The second approach relied on the fact that, in the presence of ${ }^{3} \mathrm{H}_{2} \mathrm{O}$, glucose synthesis from pyruvate leads to ${ }^{3} \mathrm{H}$ incorporation in $\mathrm{C}-1, \mathrm{C}-3, \mathrm{C}-4, \mathrm{C}-5$ and $\mathrm{C}-6$ of glucose while ${ }^{3} \mathrm{H}$ labelling at $\mathrm{C}-2$ occurs via glucose-6-phosphate isomerase (EC 5.3.1.9). Under this circumstance the relative specific radioactivities of ${ }^{3} \mathrm{H}$ in $\mathrm{C}-2$ and $\mathrm{C}-6$ of glucose or glycogen are proportional to the contribution of direct $v$. indirect pathways of glucose or glycogen synthesis.

The third method, which to some extent serves as a prelude to the more recent stable isotopic work, used $\left[\mathrm{U}-{ }^{14} \mathrm{C}\right]$ glucose followed by fragmentation of the glucose and glycogen molecules to measure the relative specific radioactivity of each $\mathrm{C}$ within plasma glucose and in glucose derived from glycogen. A derivative of this method uses 1- or 6- ${ }^{14} \mathrm{C}$-labelled (or ${ }^{13} \mathrm{C}$-labelled; see Wehmeyer et al. 1994) glucose as tracer and compares the relative isotopic enrichments of the C-1 and C-6. Appearance of label in C-6 during a $\left[1{ }^{14} \mathrm{C}\right]$ glucose infusion can then be used to calculate the contribution of recycled glucose to glycogen synthesis.

\section{METABOLISM OF U-13 C-LABELLED COMPOUNDS}

A principal disadvantage of radiotracers in the study of the details of $\mathrm{C}$ metabolism is that the raw data are atomic isotopic enrichments, i.e. the proportion of all $\mathrm{C}$ atoms that are ${ }^{14} \mathrm{C}$ (the mass spectrometric equivalent is the expression of isotopic enrichments as atoms percent excess). Gaining further metabolic information requires chemical fragmentation of ${ }^{14} \mathrm{C}$-labelled molecules to give information on the isotopic enrichments of each C.

Some 8 years ago Kalderon et al. (1986) proposed that stable isotopic approaches provided distinct advantages over the use of radioisotopes in probing the details of glucose metabolism and they, and others (Brainard et al. 1989) have applied both nuclear magnetic resonance (NMR) and gas-chromatography-mass spectrometry (GC-MS) to analyse samples obtained during $\left[\mathrm{U}-{ }^{13} \mathrm{C}\right]$ glucose infusions. NMR techniques are discussed elsewhere in this workshop.

The application of selective ion monitoring of the mass spectrum of a given molecule allows the quantification of the numbers of analyte molecules that bear $1,2, \ldots x$ atoms of the isotope (where $x$ is the total number of the given atoms in the molecule). The data obtained from experiments using $\mathrm{U}-{ }^{13} \mathrm{C}$-labelled tracers and selective-ion-monitoring GC-MS enable at least two types of investigation. In the first, the presence of the uniformly labelled precursor molecule allows the unequivocal identification of tracer molecules that have been incorporated intact into a given endproduct (such as glycogen or protein) or compartment (such as plasma). In an experiment with [U-13 C]glucose the chances of $[\mathrm{M}+6]$ glucose (glucose labelled at all six $\mathrm{C}$ atoms with ${ }^{13} \mathrm{C}$ ) arising from biosynthesis are very low, therefore, this isotopomer provides what is, in effect, a non-recyling tracer. We (Berthold et al. 1991) have used this assumption to examine the 


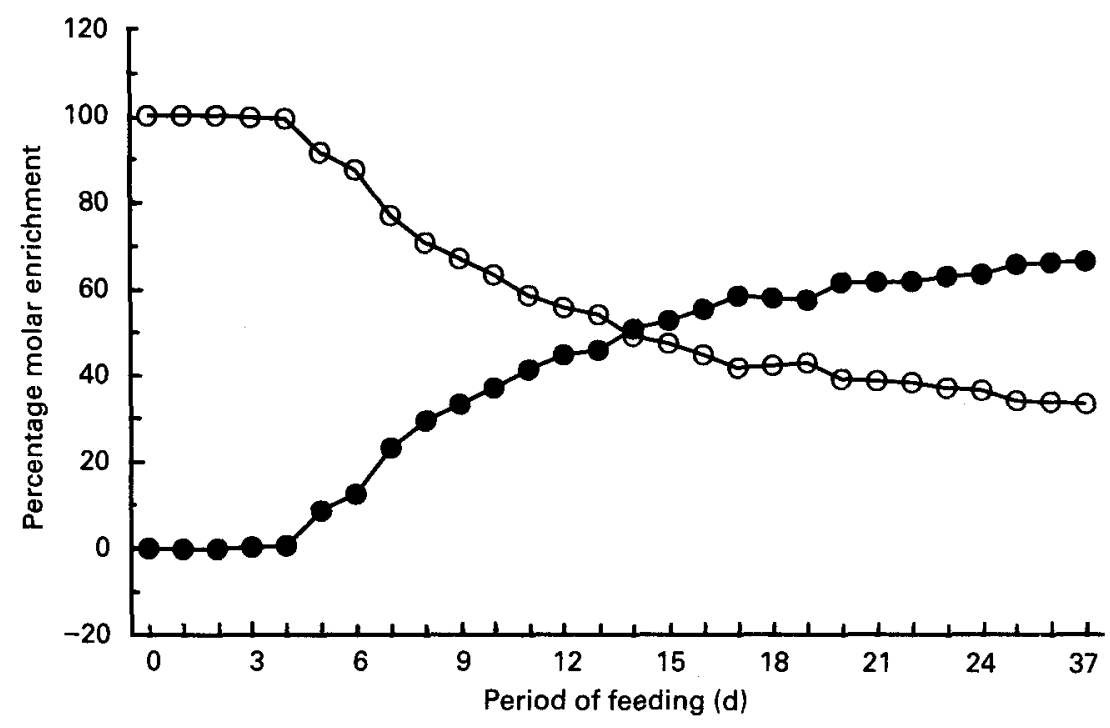

Fig. 1. The molar enrichment of unlabelled $(O)$ and uniformly labelled $(O)$ isotopomers of phenylalanine in the yolks of eggs laid by a hen consuming $\mathrm{U}-{ }^{13} \mathrm{C}$-labelled Spirulina platensis algae.

Table 1. The molar enrichment (mol tracer 100 mol tracee) in avian liver nucleosides after feeding on a diet containing $U{ }^{13} \mathrm{C}$-labelled Spirulina nucleic acids for $28 d$ (Data from Berthold et al. 1994)

\begin{tabular}{|c|c|c|c|c|c|c|c|c|c|c|c|}
\hline $\begin{array}{l}\text { Mass } \\
\text { isotopomer. }\end{array}$ & $\mathbf{M}$ & $\mathbf{M}+1$ & $M+2$ & $M+3$ & $M+4$ & $M+5$ & $M+6$ & $\mathbf{M}+7$ & $\mathbf{M}+8$ & $\mathbf{M}+9$ & $M+10$ \\
\hline Adenosine & $50 \cdot 66$ & $22 \cdot 32$ & $13 \cdot 27$ & $7 \cdot 86$ & $3 \cdot 32$ & $1 \cdot 19$ & 0.39 & 0.43 & $0 \cdot 36$ & $0 \cdot 20$ & $0 \cdot 12$ \\
\hline Guanosine & $60 \cdot 19$ & $25 \cdot 10$ & $10 \cdot 23$ & 3.05 & 0.53 & 0.39 & 0.21 & $0 \cdot 10$ & 0.07 & 0.06 & 0.07 \\
\hline Cytidine & $57 \cdot 44$ & $2 \cdot 48$ & $4 \cdot 71$ & $4 \cdot 54$ & $1 \cdot 12$ & 0.00 & 0.46 & $1 \cdot 57$ & $5 \cdot 67$ & $21 \cdot 93$ & - \\
\hline Uridine & $48 \cdot 21$ & $5 \cdot 39$ & $2 \cdot 51$ & $1 \cdot 51$ & 2.00 & 1.00 & 0.96 & $2 \cdot 20$ & $7 \cdot 38$ & 28.85 & - \\
\hline
\end{tabular}

$M$, unlabelled material; $M+1$ to $M+10, M+x$ are the different isotopomers in which $x$ is the total number of $\mathrm{C}$ atoms within any one molecule that are labelled $\left({ }^{13} \mathrm{C}\right)$.

movement of dietary organic nutrients from the diet into body proteins, triacylglycerols and nucleic acids (Fig. 1) and showed, for example, that dietary pyrimidine (but not purine) nucleosides are incorporated into hepatic nucleic acids (Berthold et al. 1994; Table 1). The second type of investigation enabled by this approach is the study of biosynthetic pathways in vivo. This is because ${ }^{13} \mathrm{C}$ incorporation into isotopomers other than the $[\mathrm{M}+x]^{13} \mathrm{C}$-isotopomer can only arise from label incorporation from other products, which in their turn were synthesized from the tracer $\left[\mathrm{U}-{ }^{13} \mathrm{C}\right]$ labelled compound. An example of this approach is provided by recent investigations concerned with the contribution of gluconeogenesis to circulating glucose (Kalderon et al. 1989, 1990; Katz et al. 1989, 1991; Lee et al. 1991; Table 2).

When $\left[\mathrm{U}-{ }^{13} \mathrm{C}\right]$ glucose is metabolized via glycolysis, pyruvate or lactate molecules so produced are also uniformly labelled. The glucose that is synthesized from these 
Table 2. Normalized glucose isotopomer ratios following the administration of $U{ }^{13} \mathrm{C}$-labelled carbohydrate to fasted rabbits, rats, piglets and humans

\begin{tabular}{lccc}
\hline \hline & $\mathrm{M}+1: \mathrm{M}+3$ & $\mathrm{M}+2: \mathbf{M}+3$ & $\mathrm{M}+3: \mathbf{M}+6$ \\
\hline Rabbits* & 0.98 & 1.02 & 0.08 \\
Rats $\dagger$ & 0.93 & 0.80 & 0.05 \\
Human subjects $\ddagger$ & 0.87 & 0.79 & 0.16 \\
Human subjects§ & 1.70 & 1.94 & 0.25 \\
Piglets\| & 1.73 & 1.37 & 0.24 \\
\hline \hline
\end{tabular}

$M+1, M+2, M+3, M+6$, different isotopomers in which there are one, two, three and six $C$ atoms respectively within any one molecule that are labelled $\left({ }^{13} \mathrm{C}\right)$.

* Lee et al. (1991); constant infusion of glucose.

$\uparrow$ Katz et al. (1989); constant infusion of glucose.

$\ddagger$ H. K. Berthold, P. J. Reeds, F. Jahoor \& P. D. Klein (unpublished results); normal adults fasted for 24 h; area under the isotopic enrichment curve $(0-6 \mathrm{~h})$ following the ingestion of U-13 C-labelled Spirulina algae.

$\S$ Kalderon et al. (1989); children with type III glycogen storage disease fasted for 9-12 $\mathrm{h}$; infusion of glucose.

$\|$ L. J. Wykes, P. J. Reeds \& F. Jahoor (unpublished results); $6 \mathrm{~kg}$ pigs fasted for 10-16 h; constant infusion of glucose.

${ }^{13} \mathrm{C}$-labelled products is obviously also labelled but, because the likelihood of two $\left[{ }^{13} \mathrm{C}_{3}\right]$ pyruvate (i.e. $[\mathrm{M}+3]$ ) molecules recombining to give $[\mathrm{M}+6]$ glucose is very low (for example, in our recent study $<1$ in $10^{3}$ ), these newly synthesized glucose molecules contain at most three labelled $\mathrm{C}$. Thus, the molar isotopic enrichment of plasma $[\mathrm{M}+6]$ glucose is a measure of the glucose entry rate and the molar isotopic enrichments of $[M+3]$ glucose: $[M+6]$ glucose ratio is a function of the proportion of the glucose entry rate that has been derived from pyruvate (i.e. via the Cori cycle). However, this method of estimating Cori cycle activity gives an underestimate (Streja et al. 1977) which arises as the result of the operation of two independent factors. First, at a number of steps in the metabolism of labelled glucose, dilution of the ${ }^{13} \mathrm{C}$ label occurs as the result of the entry of unlabelled intermediates derived from other metabolic pathways. It seems likely that, quantitatively, the most important dilution occurs in the pyruvate and oxaloacetate pools because these rapidly equilibrate with alanine and aspartate and, hence, body and dietary protein. The second factor underlying the underestimate was recognized in earlier studies with $\left[{ }^{14} \mathrm{C}\right]$ glucose (Streja et al. 1977 ) and is illustrated by the data in Table 2. Examination of the mass isotopomers of plasma glucose derived from the metabolism of a tracer $[M+6]$ glucose shows the presence of a high isotopic enrichment of the $[M+1]$ and $[\mathrm{M}+2]$-isotopomers. The presence of these isotopomers has the result that the measurement of the molar enrichment of $[M+3]$ glucose underestimates the degree of ${ }^{13} \mathrm{C}$ recycling. This complex label pattern arises from what Katz termed 'intramolecular' (i.e. isotopomer) dilution and is a reflection of the complexities of the $\mathrm{C}$ transactions in the TCA cycle.

The reactions catalysed by malate dehydrogenase $(E C$ 1.1.1.37) and fumarase $(E C$ 4.2.1.2) are close to equilibrium so that the rate of oxaloacetate turnover is the summation of the rates of the TCA cycle activity (citrate synthase (EC 4.1.3.7) activity), gluconeogenesis (phosphoenolpyruvate carboxykinase activity) and the rate of the oxaloacetate-malate-fumarate cycle. Because fumarate is also a symmetrical molecule, 
the operation of the oxaloacetate-malate-fumarate cycle in the presence of an input of $[M+3]$ oxaloacetate results in the production of a mixture of $[M+3]_{C-2-C-4^{-}}$and $[M+3]$ $\mathrm{C}-1-\mathrm{C}-3 \mathrm{Oxaloacetate}$. When these two positional isomers of $[\mathrm{M}+3]$ oxaloacetate are decarboxylated they yield $[\mathrm{M}+3]-$ and $[\mathrm{M}+2]$ phosphoenolpyruvate respectively and, thence, $[M+3]-$ and $[M+2]$ glucose. At complete positional label equilibration only $50 \%$ of the $[M+3]$ oxaloacetate gives $[M+3]$ glucose. As a first approximation, the ratio of the molar isotopic enrichments of $[\mathrm{M}+2]$ glucose: $[\mathrm{M}+3]$ glucose is a function of contribution of the oxaloacetate-malate-fumarate cycle to total oxaloacetate flux. However, a portion of the labelled oxaloacetate enters the TCA cycle. On the first turn of the TCA cycle $\mathrm{C}-1$ and $\mathrm{C}-4$ of oxaloacetate are lost at the isocitrate (C-1) and $\alpha$-ketoglutarate (C-4) dehydrogenase steps so that the metabolism of $[\mathrm{M}+3]$ oxaloacetate leads to the synthesis of $[M+2]_{C-3}-{ }_{C-4}$ fumarate and, thence, a mixture of $[M+2]_{C-1}-\mathrm{C}-2$ and $[M+2]$ $\mathrm{C}-3-\mathrm{C}-40 x a$ loacetate. A portion of this enters gluconeogenesis (giving [M+2]- and $[\mathrm{M}+1]$ glucose) and a portion undergoes a second cycle of TCA metabolism, ultimately yielding $[\mathbf{M}+1]$ glucose.

Providing no pyruvate-C enters the TCA cycle via acetyl-CoA (see p. 351), the ratios of the isotope enrichments of $[M+1]-,[M+2]-$ and $[M+3]$ glucose, following the administration of a $[\mathrm{M}+6]$ glucose tracer allows the derivation of three variables of oxaloacetate metabolism (Katz et al. 1989; Lee et al. 1991):

$A$ is a measure of the distribution of $[\mathrm{M}+3]$ oxaloacetate between the $\mathrm{C}-1-\mathrm{C}-3$ and $\mathrm{C}-2-\mathrm{C}-4$ positional isotopomers and, hence, a measure of relative values of net and total oxaloacetate flux. $A$ can have a value of between 0.5 (complete equilibration between

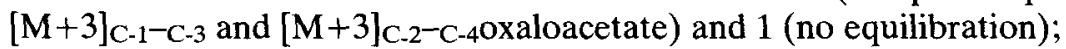

$R$ is the proportion of oxaloacetate flux that is metabolized to citrate;

$Y$ is the flux of pyruvate carboxylase relative to the net oxaloacetate flux i.e. the ratio, pyruvate carboxylase:citrate synthase.

Calculations of these variables from the data in Table 2, using the equations of Katz et al. (1989) and Lee et al. (1991), are shown in Table 3. Values for $A$ ranged from $0 \cdot 76$ to $0 \cdot 52$; they correspond to a range of [M+3] oxaloacetate positional label randomization of between 40 and $92 \%$. Pyruvate carboxylation contributed between 37 and $90 \%$ of the net flux of oxaloacetate. Between 53 and $73 \%$ of the net oxaloacetate flux was metabolized by citrate synthase. The calculations suggested that between 30 and $50 \%$ of hepatic glucose output under these circumstances was derived via the Cori cycle.

Table 3. Calculated values for the three variables of oxaloacetate metabolism

\begin{tabular}{|c|c|c|c|c|}
\hline & $A$ & $R$ & $Y$ & Reference \\
\hline Rabbits & $0 \cdot 58$ & 0.53 & 0.90 & Lee et al. (1991) \\
\hline Rats & $0 \cdot 72$ & 0.59 & 0.69 & Katz et al. (1989) \\
\hline Humans & $0 \cdot 76$ & 0.59 & 0.69 & $\begin{array}{l}\text { H. K. Berthold, P. J. Reeds, F. Jahoor } \\
\text { \& P. D. Klein (unpublished results) }\end{array}$ \\
\hline Humans & $0 \cdot 51$ & 0.64 & 0.56 & Kalderon et al. (1989) \\
\hline Pigs & 0.57 & 0.73 & $0 \cdot 37$ & $\begin{array}{l}\text { L. Wykes, P. J. Reeds \& F. Jahoor } \\
\text { (unpublished results) }\end{array}$ \\
\hline
\end{tabular}

$A$, a measure of the distribution of $[\mathrm{M}+3]$ oxaloacetate between $\mathrm{C}-1-\mathrm{C}-3$ and $\mathrm{C}-2-\mathrm{C}-4$ positional isotopomers, where $\left[\mathrm{M}+3\right.$ ] oxaloacetate is the isotopomer in which three $\mathrm{C}$ atoms are labelled $\left({ }^{13} \mathrm{C}\right) ; R$, proportion of oxaloacetate flux that is metabolized to citrate; $Y$, flux of pyruvate carboxylase $(E C$ 6.4.1.1) relative to the net oxaloacetate flux, i.e. pyruvate carboxylase:citrate synthase (EC 4.1.3.7). 
Table 4. The molar isotopic enrichment (mol tracer/100 mol tracee) of [M+3]lactate, pyruvate and alanine in plasma and that of $[M+3]$ alanine in plasma VLDL. apolipoprotein B (apoB)-100 (Data from Jahoor et al. 1994)

(Measurements in fasted piglets during an infusion of $\left[\mathrm{U}-{ }^{13} \mathrm{C}\right]$ glucose)

\begin{tabular}{|c|}
\hline Plasma lactate \\
\hline Plasma pyruvate \\
\hline Plasma alanine \\
\hline ApoB-100-alanine \\
\hline
\end{tabular}

$\mathrm{M}+3$, isotopomer in which three $\mathrm{C}$ atoms within any one molecule are labelled with ${ }^{13} \mathrm{C}$.

The application of this stable isotopic approach was a significant advance but still suffered from two problems. First, the data are largely derived from plasma metabolites and as such do not directly measure the labelling of the intracellular metabolite pools. This is, of course, a problem common to many other isotopic studies of metabolism in vivo. In animal experiments this disadvantage can be circumvented by direct tissue sampling but this is a major disadvantage in human studies and has necessitated the development of indirect approaches to measuring intracellular (especially intrahepatic) isotopic enrichments. Second, as pointed out by Katz et al. (1989), the metabolic model cannot accommodate significant metabolism of $\left[{ }^{13} \mathrm{C}\right]$ pyruvate by pyruvate dehydrogenase. This limits the general application of the model.

In regard to the first of these problems, various approaches, based on hepatic detoxification mechanisms, have been devised. Thus, the isotopic enrichment of the glucose moiety of UDP-glucose has been estimated from measurements of urinary glucuronides (Hellerstein et al. 1987). Hellerstein et al. (1991) have also estimated the isotopic enrichment of hepatic acetyl-CoA by measuring that of the acetyl derivative of sulphamethoxazole in urine. Measurements of the glutamine conjugate of phenylacetic acid have been used to estimate the intrahepatic enrichment of glutamate-glutamine (Magnussun et al. 1991; Schumann et al. 1991). We (Reeds et al. 1992; Jahoor et al. 1994) have exploited the rapid turnover rate of VLDL-apolipoprotein B-100 (apoB-100) to use the equilibrium isotopic enrichments of its substituent amino acids to infer the isotopic enrichment of hepatic amino acids and, thence, the isotopic enrichments of their $\alpha$-keto amino group acceptors (Table 4).

The ability to measure intrahepatic alanine, aspartate and glutamate isotopic labelling offers a solution to the theoretical problem of the Katz et al. (1989) and Lee et al. (1991) model. Kelleher (1986) pointed out that analysis of the label distribution in either citrate or $\alpha$-ketoglutarate, following the introduction of $\mathrm{C}$-labelled glucose or lactate, allowed the derivation of a model that could encompass entry of labelled pyruvate into the TCA cycle both via oxaloacetate and via acetyl-CoA. The approach relies on the fact that $\mathrm{C}-1$ and C-2 of citrate derive from acetyl-CoA while oxaloacetate supplies C-3-C-6 of citrate and, thence, C-3-C-5 of ketoglutarate (glutamate). The observation has been exploited in experiments in which either $\left[3-{ }^{14} \mathrm{C}\right]$ lactate (Magnusson et al. 1991) or $\left[3-{ }^{13} \mathrm{C}\right]$ lactate (Di Donato et al. 1993) were given to human beings and rats respectively. Both groups then isolated (either from phenylacetyl-glutamine in the urine (Magnusson et al. 1991) or directly from liver samples (Di Donato et al. 1993)) glutamate and subjected it to 
fragmentation to measure the isotopic enrichment of each $\mathrm{C}$. This then allowed the calculation of the relative rates of TCA cycle activity, the magnitude of the oxaloacetatefumarate cycle as well as the relative rates of pyruvate carboxylation and dehydrogenation. Both groups concluded that, under fasting conditions, the rate of oxaloacetate-fumarate cycling was more than 5-fold higher than the net flux of oxaloacetate (i.e. positional isomerization in oxaloacetate was at least $83 \%$ complete) and that there was negligible $(<5 \%)$ contribution of acetyl-CoA derived from pyruvate to the TCA cycle. However, Magnusson et al. (1991) went on to conclude that in the fed condition, pyruvate contributed about $40 \%$ of the acetyl-CoA entering the cycle.

Although Di Donato et al. (1993) reported a particularly elegant combination of enzymic, chemical and selective-ion-monitoring methods for obtaining the necessary information, the technique is still comparatively laborious. We have recently commenced an examination of the utility of an alternative approach in which [U-13 C] glucose is used as tracer and the ${ }^{13} \mathrm{C}$-mass isotopomer distributions of alanine, aspartate and glutamate isolated from VLDL-apoB-100 are used to infer the isotopomer distributions of hepatic pyruvate, oxaloacetate and $\alpha$-ketoglutarate respectively. Preliminary measurements of the abundances of the isotopomers of these amino acids during the infusion of $\left[\mathrm{U}-{ }^{13} \mathrm{C}\right]$ glucose into piglets are shown in Table 4.

The problem is to calculate the proportion of acetyl-CoA entering the TCA cycle from pyruvate, as opposed to acetyl-CoA derived from other sources, for example, fatty acid $\beta$-oxidation. The analysis that we have adopted relies on three assumptions:

(1) that the labelling of apoB-100 alanine, aspartate and glutamate, during an infusion of $\left[\mathrm{U}-{ }^{13} \mathrm{C}\right] \mathrm{glucose}$, is a direct reflection of the labelling of pyruvate, oxaloacetate and $\alpha$-ketoglutarate;

(2) that, under the conditions of this experiment, $[\mathrm{M}+3] \alpha$-ketoglutarate (glutamate) can only derive from $[\mathrm{M}+3]_{\mathrm{C}-2-\mathrm{C}-4 \mathrm{Oxaloace}}$ ate (aspartate);

(3) that significant labelling of [M+2]glutamate derives from three sources:

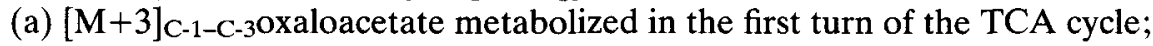

(b) $[\mathrm{M}+2]$ oxaloacetate metabolized in the second turn of the TCA cycle;

(c) $[\mathrm{M}+2]$ acetyl-CoA derived from $[\mathrm{M}+3]$ pyruvate.

Our approach aims, first to calculate the contribution of oxaloacetate to the $[\mathrm{M}+2]$ isotopomer of glutamate and to ascribe any differences between the measured and predicted values to the incorporation of $[\mathrm{M}+2]$ acetyl-CoA derived from pyruvate. It follows from assumption 2 that the ratio of the molar enrichments of $[M+3]$ glutamate:[M+3]aspartate is a measure of the degree of equilibration of the two positional isotopomers of $[\mathrm{M}+3]$ oxaloacetate. At complete equilibration [M+3]glutamate:[M+3] aspartate will be 0.5 . The measured value was 0.41 , implying $82 \%$ equilibration. This value is very close to the value calculated by both Magnusson et al. (1991) and Di Donato et al. (1993).

$[\mathrm{M}+3]$ oxaloacetate, metabolized in the first turn of the TCA cycle, will yield $[\mathrm{M}+2]_{\mathrm{C}-3-\mathrm{C}-4 \mathrm{fumarate}}$ irrespective of the original position of the three ${ }^{13} \mathrm{C}$ atoms in the starting oxaloacetate. The isotopic enrichment of $[\mathrm{M}+2]$ oxaloacetate derived from the first turn of the cycle will equal that of the $[\mathrm{M}+3]$ oxaloacetate from which it derived. Thus, at a maximum, the isotopic enrichment of $[\mathrm{M}+2]$ glutamate derived from $[\mathrm{M}+2]$ oxaloacetate metabolized in the second turn of the TCA cycle will be the same isotopic enrichment as $[\mathrm{M}+3]$ aspartate.

Using this reasoning we have made the following calculations for the data shown in 
Table 5. The molar enrichment of different mass isotopomers of VLDL-apolipoprotein $B-100$-bound alanine, glutamate and aspartate during an infusion of [U-13 C]glucose in fasted piglets (L. Wykes, F. Jahoor and P. J. Reeds, unpublished results)

\begin{tabular}{lccc}
\hline Mass isotopomer . . & $\mathrm{M}+1$ & $\mathrm{M}+2$ & $\mathrm{M}+3$ \\
\hline Alanine & 0.77 & 0.69 & 2.33 \\
Aspartate & 0.97 & 0.60 & $0 \cdot 54$ \\
Glutamate & 1.03 & 1.15 & 0.22 \\
\hline
\end{tabular}

$\mathrm{M}+1, \mathrm{M}+2, \mathrm{M}+3$, different isotopomers in which there are one, two and three $\mathrm{C}$ atoms respectively within any one molecule that are labelled $\left({ }^{13} \mathrm{C}\right)$.

Table 5: the molar isotopic enrichment ( $\mathrm{mol}$ tracer $/ 100$ mol tracee) of $[\mathrm{M}+2]$ glutamate is $1 \cdot 15$. Of this $0 \cdot 32$ (i.e.

$$
\left.\left(1-\frac{0.22}{0.54}\right) \times 0.54\right)
$$

is derived from the metabolism of $[\mathrm{M}+3]_{\mathrm{C}-1-\mathrm{C}-3 \mathrm{Oxaloacetate}}$ in the first turn of the TCA cycle and a further 0.54 (i.e. the molar isotopic enrichment of [M+3]aspartate) is due to the metabolism of $[\mathrm{M}+2]$ oxaloacetate in the second turn of the TCA cycle. At a first approximation the remainder, $\mathbf{0} \cdot 29$, could be ascribed to the entry of $[\mathrm{M}+2]$ acetyl-CoA derived from $[\mathrm{M}+3]$ pyruvate. This suggests that $25 \%$ of the $\alpha$-ketoglutarate is metabolized by the TCA cycle in the liver and $55 \%$ of the hepatic glucose output of postabsorptive piglets derives from pryuvate metabolism.

\section{CONCLUSION}

In this necessarily brief account we have attempted to demonstrate that recent developments in the application of uniformly-labelled tracers coupled with selective-ionmonitoring GC-MS offers a practicable approach to the study of metabolic interrelationships in vivo. Many problems remain. Some interpretations, particularly with respect to the contribution of gluconeogenesis to glucose entry, can be made with confidence and we find it reassuring that three independent methods of estimating the degree of label equilibration in oxaloacetate give reasonable agreement. Nevertheless unequivocal conclusions will necessarily require further information on the positions within a given metabolite into which label has been incorporated. Results obtained to date also suggest the presence of extensive metabolic compartmentation, both between and within cells, and this demands the continued development of methods for the non-invasive sampling of the cellular (and subcellular) pools of metabolic intermediates. However, despite these caveats, approaches that have been facilitated by the development of appropriate instrumentation now offer new opportunities to identify whether the complex multicellular organism functions as classical (bacterial) biochemistry implies.

This work is a publication of the USDA/ARS Children's Nutrition Research Center, Department of Pediatrics, Baylor College of Medicine and Texas Children's Hospital, Houston, TX. Funding has been provided from the USDA/ARS under Cooperative 
Agreement no. 58-6250-1-003. The contents of this publication do not necessarily reflect the views or policies of the USDA, nor does mention of trade names, commercial products, or organizations imply endorsement by the US Government.

\section{REFERENCES}

Berthold, H. K., Crain, P., Reeds, P. J. \& Klein, P. D. (1994). Dietary pyrimidines but not dietary purines make a significant contribution to nucleic acid synthesis. Proceedings of the National Academy of Sciences, USA (In the Press).

Berthold, H. K., Hachey, D. L., Reeds, P. J., Thomas, O. P., Hoeksma, S. \& Klein, P. D. (1991). Uniformly labeled algal protein used to determine amino acid essentiality in vivo. Proceedings of the National Academy of Sciences, USA 88, 8091-8095.

Brainard, J. R., Downey, R. S., Bier, D. M. \& London, R. E. (1989). Use of multiple ${ }^{13}$ C-labeling strategies and ${ }^{13} \mathrm{C}$ NMR to detect low levels of exogenous metabolites in the presence of large endogenous pools; measurement of glucose turnover in a human subject. Analytical Biochemistry 176, 307-312.

Di Donato, L., Des Rosiers, C., Montgomery, J. A., Davis, F., Garneau, M. \& Brunengraber, H. (1993). Rates of gluconeogenesis and citric acid cycle in perfused livers, assessed from the mass spectrometric assay of the ${ }^{13} \mathrm{C}$-labeling pattern of glutamate. Journal of Biological Chemistry 268, 4170-4180.

Hellerstein, M. K., Christiansen, M., Kaempher, S., Kletke, C., Wu, K., Reid, J. S., Mulligan, K., Hellerstein, N. S. \& Shackleton, C. H. L. (1991). Measurement of de novo hepatic lipogenesis in humans using stable isotopes. Journal of Clinical Investigation 87, 1841-1852.

Hellerstein, M. K., Greenblatt, D. J. \& Munro, H. N. (1987). Glycoconjugates as noninvasive probes of intrahepatic metabolism: I. Kinetics of label incorporation with evidence of a common precursor UDP-glucose pool for secreted glycoconjugates. Metabolism 36, 988-994.

Hems, D. A., Whitton, P. D. \& Taylor, E. A. (1972). Glycogen synthesis in the perfused liver of the fasted rat. Biochemical Journal 129, 529-538.

Jahoor, F., Reeds, P. J. \& Burrin, D. G. (1994). Measurements of plasma protein synthesis in the infant pig: a new stable isotopic approach using uniformly ${ }^{13} \mathrm{C}$-labeled glucose. American Journal of Physiology (In the Press).

Kalderon, B., Gopher, A. \& Lapidot, A. (1986). Metabolic pathways leading to liver glycogen repletion in vivo studied by GC-MS and NMR. FEBS Letters 204, 29-32.

Kalderon, B., Korman, S. H., Gutman, A. \& Lapidot, A. (1989). Glucose recycling and production in glycogenosis type I and III: stable isotope technique study. American Journal of Physiology 257, E346-E353.

Katz, J., Kuwajima, M., Foster, D. W. \& McGarry, J. D. (1986). The glucose paradox: new perspectives on hepatic carbohydrate metabolism. Trends in Biochemical Science 11, 136-140.

Katz, J., Lee, W.-N. P., Wals, P. A. \& Bergner, E. A. (1989). Studies of glycogen synthesis and the Kreb's cycle by mass isotopomer analysis with $\left[\mathrm{U}-{ }^{13} \mathrm{C}\right]$ glucose in rats. Journal of Biological Chemistry 264, 12994-13001.

Katz, J. \& McGarry, J. D. (1984). The glucose paradox. Is glucose a substrate for liver metabolism? Journal of Clinical Investigation 74, 1901-1909.

Katz, J., Wals, P. A. \& Lee, W.-N. P. (1991). Determination of pathways of glycogen synthesis and the dilution of the three-carbon pool with $\left[\mathrm{U}-{ }^{13} \mathrm{C}\right]$ glucose. Proceedings of the National Academy of Sciences, USA 88, 2103-2107.

Kelleher, J. K. (1986). Gluconeogenesis from labeled carbon: estimating isotope dilution. American Journal of Physiology 250, E296-E305.

Kelleher, J. K. \& Masterson, T. M. (1992). Model equations for condensation biosynthesis using stable isotopes and radioisotopes. American Journal of Physiology 262, E118-E125.

Lee, W.-N. P., Sorou, S. \& Bergner, E. A. (1991). Glucose isotope, carbon recycling and gluconeogenesis using $\left[\mathrm{U}-{ }^{13} \mathrm{C}\right]$ glucose and mass isotopomer analysis. Biochemical Medicine and Metabolic Biology 45, 298-305.

McGarry, J. D., Kuwajima, M., Newgard, C. B., Foster, D. W. \& Katz, J. (1987). From dietary glucose to liver glycogen: The full circle around. Annual Review of Nutrition 7, 51-73.

Magnusson, I., Schumann, W. C., Bartsch, G. E., Chandramouli, V., Kumaran, K., Wahren, J. \& Landau, B. R. (1991). Noninvasive tracing of Kreb's cycle metabolism in liver. Journal of Biological Chemistry 266, $6875-6984$. 
Newgard, C. B., Hirsch, L. J., Foster, D. W. \& McGarry, J. D. (1983). Studies on the mechanism by which exogenous glucose is converted to liver glycogen in the rat. A direct or indirect pathway. Journal of Biological Chemistry 258, 8046-8052.

Reeds, P. J., Hachey, D. L., Patterson, B. W., Motil, K. J. \& Klein, P. D. (1992). VLDL apolipoprotein B-100, a potential indicator of the isotopic labeling of the hepatic protein synthetic precursor pool in humans: Studies with multiple stable isotopically labeled amino acids. Journal of Nutrition 122, 457-467.

Schumann, W. C., Magnusson, I., Chandramouli, V., Kumaran, K., Wahren, J. \& Landau, B. R. (1991). Metabolism of $\left[2{ }^{14} \mathrm{C}\right]$ acetate and its use in assessing hepatic Krebs cycle activity and gluconeogenesis. Journal of Biological Chemistry 266, 6985-6990.

Scofield, R. F., Kosugi, K., Schumann, W. C., Kumaran, K. \& Landau, B. R. (1985). Quantitative estimate of the pathways followed in the conversion to glycogen of glucose administered to the fasted rat. Journal of Biological Chemistry 260, 8777-8782.

Seglen, P. O. (1974). Autoregulation of glycolysis, respiration, gluconeogenesis and glycogen synthesis in isolated parenchymal tat liver cells under aerobic or anaerobic conditions. Biochimica et Biophysica Acta 338, 317-336.

Streja, D. A., Steiner, S., Marliss, E. B. \& Vranic, M. (1977). Turnover and recycling of glucose in man during prolonged fasting. Metabolism 26, 1089-1098.

Sugden, M. C., Watts, D. I., Palmer, T. \& Myles, N. (1983). Direction of carbon flux in starvation and after refeeding: in vitro and in vivo effects of 3-mercaptopicolinate. Biochemistry International 7, 329-337.

Wehmeyer, N., Gunderson, H., Nauman, J., Savage, S. \& Hartzell, C. (1994). Determination of glycogen synthesis pathway by ${ }^{13} \mathrm{C}$ nuclear magnetic resonance analysis. Metabolism 43, 38-43. 